\title{
Biological Aunt
}

National Cancer Institute

\section{Source}

National Cancer Institute. Biological Aunt. NCI Thesaurus. Code C96569.

A female relative who is a sibling of either of the biological parents, and who share a common ancestor. 